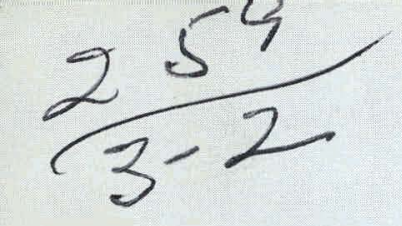

\title{
EVALUATION OF SEVERAL METHODS OF DETECTING URANIUM PARTICULATES \\ IN A DISPOSAL STACK AT THE OAK RIDGE Y-12 PLANT
}

R. A. Gallman

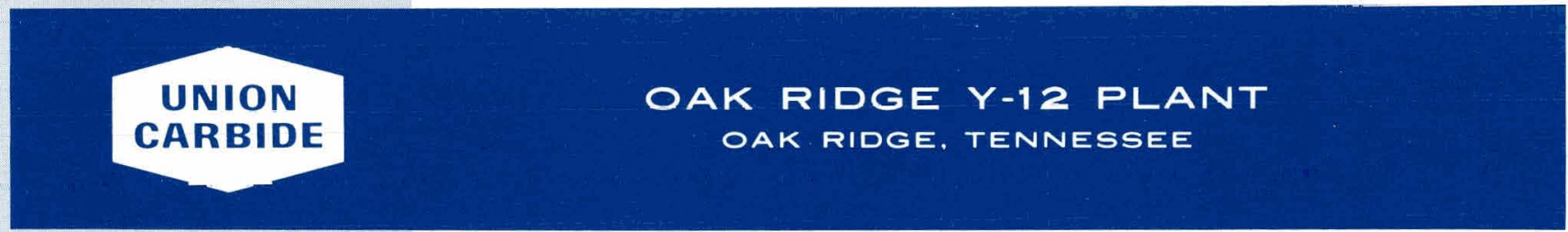

prepared for the U.S. ATOMIC ENERGY COMMISSION

under U.S. GOVERNMENT Contract W.7405 eng 26

\section{MASTER}




\section{DISCLAIMER}

This report was prepared as an account of work sponsored by an agency of the United States Government. Neither the United States Government nor any agency Thereof, nor any of their employees, makes any warranty, express or implied, or assumes any legal liability or responsibility for the accuracy, completeness, or usefulness of any information, apparatus, product, or process disclosed, or represents that its use would not infringe privately owned rights. Reference herein to any specific commercial product, process, or service by trade name, trademark, manufacturer, or otherwise does not necessarily constitute or imply its endorsement, recommendation, or favoring by the United States Government or any agency thereof. The views and opinions of authors expressed herein do not necessarily state or reflect those of the United States Government or any agency thereof. 


\section{DISCLAIMER}

Portions of this document may be illegible in electronic image products. Images are produced from the best available original document. 
Printed in the United States of America. Available from

National Technical Information Service

U.S. Department of Commerce

5285 Port Royal Road, Springfield, Virginia 22151

Price: Printed Copy \$3.00; Microfiche \$0.95

This report was prepared as an account of work sponsored by the United States Government. Neither the United States nor the United States Atomic Energy Commission, nor any of their employees, nor any of their contractors, subcontractors, or their employees, makes any warranty, express or implied, or assumes any legal liability or responsibility for the accuracy, completeness or usefulness of any information, apparatus, product or process disclosed, or represents that its use would not infringe privately owned rights. 


\title{
EVALUATION OF SEVERAL METHODS OF DETECTING URANIUM \\ PARTICULATES IN A DISPOSAL STACK AT THE OAK RIDGE Y-12 PLANT
}

\author{
R. A. Gallman
}

Oak Ridge $Y-12$ Plant

P.O. Box Y. Oak Ridge, Tennessee $\mathbf{3 7 8 3 0}$

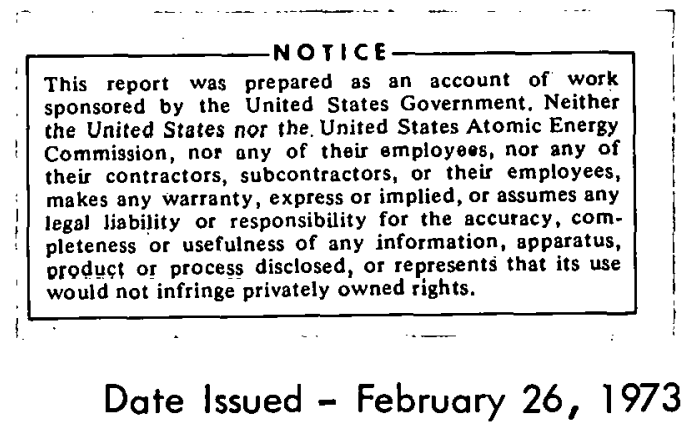

Prepared for the U.S. Atomic Energy Commission Under U.S. Government Contract W-7405eng-26 
THIS PAGE

\section{WAS INTENTIONALLY \\ LEFT BLANK}




\begin{abstract}
Four methods of monitoring the radioactivity from highly enriched uranium were evaluated as to their suitability for determining whether any significant amount of enriched material escapes into the air through an effluent stack at the Oak Ridge Y-12 Plant. Experimental work showed that two methods: (1) alpha energy discrimination, and (2) X-ray energy analysis can perform the measurement as required while maintaining a simplicity of operation and at a reasonable cost. Significant improvements can be made in both methods, but not without increasing the complexity of operation as well as the cost.
\end{abstract}




\section{CONTENTS}

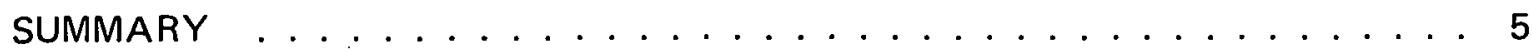

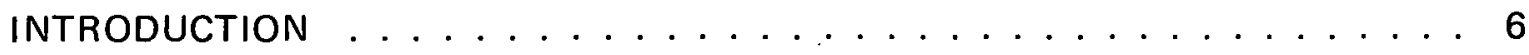

DETECTING ENRICHED URANIUM PARTICULATES . . . . . . . . . . 7

Pertinent Basic Information . . . . . . . . . . . . . . . 7

Decay Sequence of Uranium-234 . . . . . . . . . . . . . 7

Decay Sequence of Radon-222 . . . . . . . . . . . . . 7

Suggested Procedures . . . . . . . . . . . . . . . . . . . . 8

Gamma Emission from Uranium-235 . . . . . . . . . . . . . . 8

Tluorescence of Uidariurir $\mathrm{L} \times \mathrm{Rays} \ldots \ldots \ldots \ldots \ldots$

Alpha Energy Discrimination . . . . . . . . . . . . . 9

X-Ray Energy Analysis . . . . . . . . . . . . . . . . . . . 12

Conclusions and Recommendations . . . . . . . . . . . . . . . . . 16

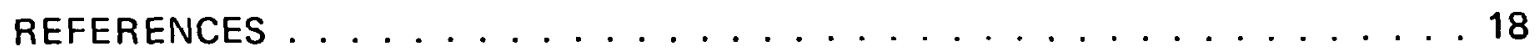

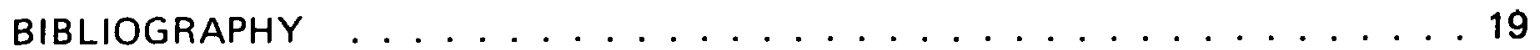




\section{SUMMARY}

Determining whether any highly enriched uranium is released from effluent disposal stacks at the Oak Ridge $Y-12$ Plant $(a)$ is important, especially from an environmental and health viewpoint. Four methods were proposed to improve the reliability of measuring this particular effluent: (1) monitor the 185-Kev gamma emissions from U-235, (2) measure the fluorescence of uranium to detect the $L X$ rays, (3) by alpha energy discrimination, and (4) by $X$-ray energy analysis.

Two of the four methods were found to be in compliance with the requirements of minimum background sensitivity and maximum enriched uranium sensitivity-alpha energy discrimimation and $\mathrm{X}$-ray energy analysis. The alpha-energy discrimination method has about one-fifth the sensitivity to background activity as the present system and a sensitivity to enriched uranium of $6.6 \mathrm{cpm}$ per microgram; however, alpha absorption and energy losses are significant drawbacks. The $\mathrm{X}$-ray energy analysis technique also has approximately one-fifth the sensitivity to background activity as the present system, but its sensitivity to enriched uranium is only $3.4 \mathrm{cpm}$ per microgram. On the other hand, this method does not have the absorption and energy-loss problems that are associated with the alpha energy discrimination method.

(a) Operated by the Union Carbide Corporation's Nuclear Division for the US Atomic Energy Commission. 


\section{INTRODUCTION}

While machining and casting highly enriched uranium (nominally $93 \%$ U-235, 1\% U-234, and $6 \%$ other uranium isotopes); particulates of this radioactive material are produced. The exhaust from these operations is passed through a series of filter bags, then to an effluent disposal stack. If any of this material reaches the stack, it would be released into the atmosphere. The U-234 component of enriched uranium is important from an environmental and health aspect due to its high specific activity, while the U-235 is the valuable end product for which strict accountability must be maintained. Thus, a detection system is required to monitor any release of enriched uranium into the stack.

The present monitoring system has been in use for about 13 years and is in need of replacement or improvement. The present system operates as follows: A probe, located in the stack effluent, collects particulate matter and deposits it on Whatman 41 filter paper After a predetermined collection period, the paper is transported to an alpha scintillation detector which counts the alpha emissions, then the cycle is repeated. A ratemeter and recorder are connected to the detector which can activate an alarm when the alpha activity exceeds a preset level. The most serious problem associated with this system is its high false alarm rate. This malfunction occurs because of the background alpha activity from naturally occurring radon and thoron and their daughter products. The alpha scintillation detector cannot distinguish between the alpha particles emitted from enriched uranium and the higher-energy alphas emitted by the radon and thoron decay series; therefore, when the radon/thoron activity is at a high level, this system registers the larger number of alphas, increasing the probability of a false alarm.

The objective of the present study was to develop an improved method of determining the amount of enriched uranium collected on a filter paper sample and yet eliminate the false alarms while maintaining adequate sensitivity. Other desirable characteristics were that it should have a low cost and be easy to operate. To meet these objectives, four methods were proposed as possible answers to the problem: (1) monitor the 185-Kev gamma emissions trom U-235 using a sodium iodide scintillation detector; (2) measure the fluorescence of uranium $L X$ rays by an $X$-ray generator or high-intensity radioactive source; (3) discriminate between the alpha energy from uranium alpha particles (mainly from U-234) and background activity; and (4) by $X$-ray energy analysis whereby thorium $L X$ rays, produced in the decay of U.234 to Th-230, are distinguished from background X-ray and low-energy gamma activity. Method 1 measures the amount of U-235 present and Method 2 measures all the uranium present, whereas Methods 3 and 4 measure only the amount of U-234 located on the filter paper. 


\section{DETECTING ENRICHED URANIUM PARTICULATES}

\section{PERTINENT BASIC INFORMATION}

\section{Decay Sequence of Uranium-234}

A majority of the alpha and $X$-ray activity from enriched uranium is due to U-234, although this isotope constitutes only one percent by weight of the enriched uranium of interest. This abnormal influence results from its high specific activity $(250 \mathrm{dps} / \mu \mathrm{gm})$ compared with that of U-235 (0.08 dps/ $/ \mathrm{gm})$. Figure 1 outlines the decay sequence of U-234. (1) Uranium-234 decays by alpha emission to the ground state of Th-230 72 percent of the time, emitting a 4.773-Mev alpha, and to an excited state of Th-230 (Th-230*) 28 percent of the time, emitting a 4.722-Mev alplid. The daughters of U-234 produce little activity since they have long half lives compared to the time that has elapsed since enrichment. The excited state of Th-230 decays to the

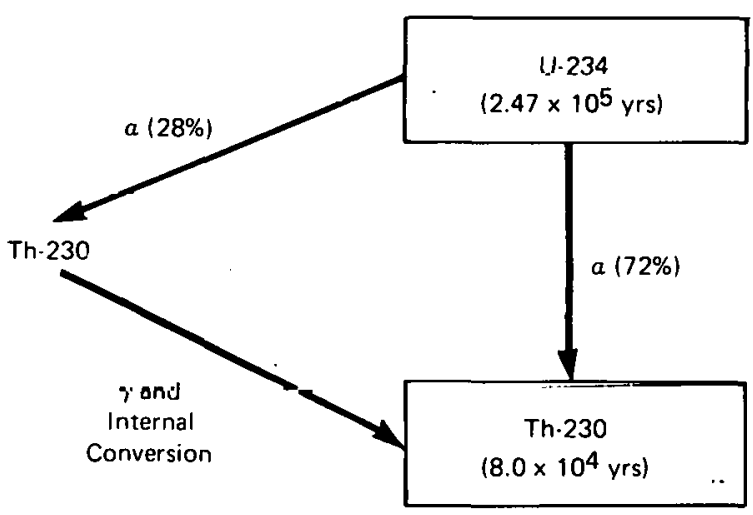

Figure 1. DECAY SEQUENCE OF URANIUM-234. ground state by gamma emission and internal conversion; however, the L-shell internal conversion coefficient is 130 , indicating that decay is almost entirely by internal conversion in which an L-shell electron is ejected from the thorium atom. When the $L$-shell vacancy is filled, $L X$ rays are emitted.

\section{Decay Sequence of Radon-222}

Radon (Rn-222), a naturally occurring member of the uranium decay series, and thoron (Rn-220), a naturally occurring member of the thorium decay series, are present throughout the soil and atmosphere in small concentrations due to the extensive deposits of trace amounts of natural uranium and thorium. Both radon and thoron are gases which, when formed, can escape to the atmosphere from porous rocks and soil. This migration from the earth to the atmosphere was termed "emanation" at the time of its discovery; hence, the early name for radon-emanation $(\mathrm{Em})$.

Radon and thoron are naturally occurring radioactive gases; however, the half life of thoron is so short (55 seconds) that little of it can escape to the atmosphere. As a result of this, radon, with its relatively long half life ( 3.8 days), and its daughter products are more prevalent than thoron in the atmosphere. Radon itself does not contribute to the background activity since, as a gas, it cannot be collected on filter paper; however, its daughters are solids and can be collected. The radon decay sequence is outlined in Figure 2 to provide a clear picture of the way the background activity (alpha particles and $X$ rays) arises. (1)

Since no radon is actually collected on the filter paper, only the 6.00-Mev alphas from Po-218 and the 7.68-Mev alphas from Po-214 will he present, and they constitute the 


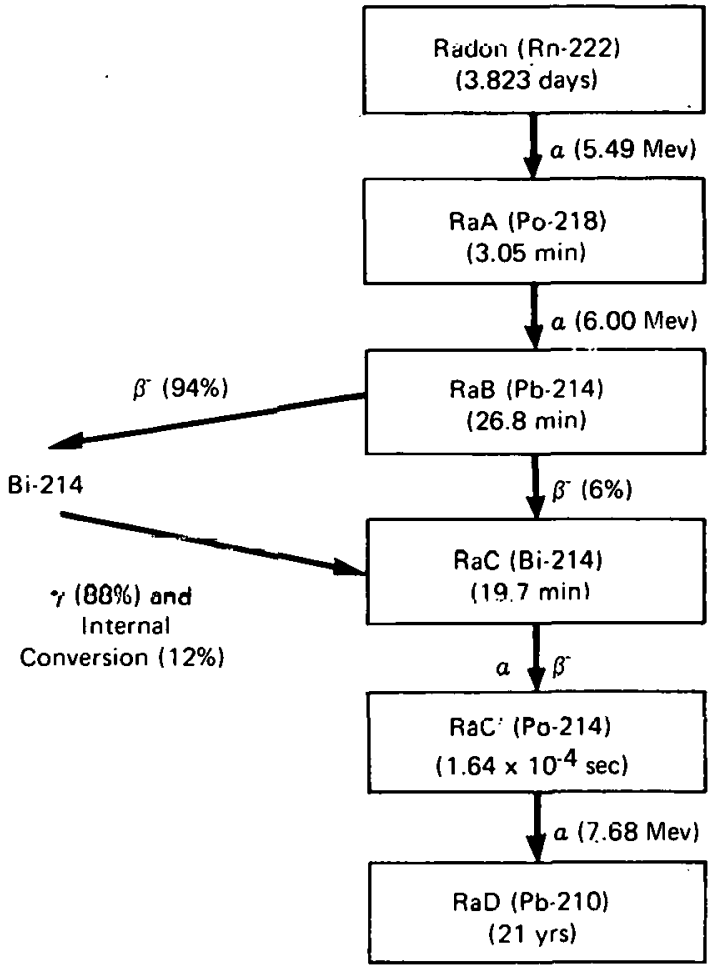

Figure 2. DECAY SEQUENCE OF RADON-222. majority of the background alpha activity. The excited state of $\mathrm{Bi}-214$ decays to the ground state by gamma emission approximately 88 percent of the time and by internal conversion 12 percent of the time. Most of the conversion electrons originate in the $\mathrm{L}$ orbit, generating the bismuth $L X$ rays.

\section{SUGGESTED PROCEDURES}

Initially, four methods of measuring the amount of uranium collected on a filter sample were proposed: (1) monitor the 185Kev gamma emissions from U-235; (2) measure the fluorescence due to the uranium $L X$ rays; (3) by an alpha energy discrimination between uranium and the background alpha particles; and (4) by an $X$-ray energy analysis to distinguish thorium $L X$ rays (from the decay of U-234 to Th-230) from the background $\mathrm{X}$-ray activity. Each method was evaluated not only concerning its ability to solve the problem, but also on its cost, its complexity of operation, and its safety features.

\section{Gamma Emission from U-235}

This method involves the use of a scintillatlon detector to monitor the 185-Kev gamma emissions from U-235. A single-channel analyzer (SCA) is used to set an energy window to include the 185-Kev gamma peak and to minimize the background contributions to the count rate. The output from the SCA is fed to a ratemeter and recorder. The major advantages of this technique are: (1) it is a direct measure of the amount of U-235 present on the filter paper (which is proportional to the total amount emitted to the atmosphere through the disposal stack), and (2) there is no absorption or energy loss as the gammas traverse the filter paper and air gap between the filter paper and detector. However, this method proved to be unworkable as a result of the very low count rate which is due to the small quantities of enriched uranium collected on a filter-paper sample, and to the low specific activity $(4.8 \mathrm{dpm} / \mu \mathrm{gm})$ of $U 235$ which yields the $185-K_{\text {ev }}$ gammas in approximately 55 percent of the decays.

To show how poor the sensitivity is due to the low count rate, assume a detector configuration with a geometric efficiency of 25 percent and the optimum SCA energy window. Under these conditions the method has a sensitivity of approximately $0.215 \mathrm{dpm}$ per microgram of the enriched uranium. This technique would require extremely long count times for small quantities; however, it could be successfully applied in situations where larger amounts of uranium are collected. 


\section{Fluorescence of Uranium $L$ X'Rays}

The fluorescence method employs a radiation source to excite the uranium so as to produce characteristic $L X$ rays. To accomplish this result, either an $X$-ray generator or a high-intensity radioactive source is required. A germanium low-energy-photon (LEP) detector is used to monitor the uranium $L X$-ray activity since good energy resolution is needed for proper identification of the energy peaks. The advantages of this method are that: (1) it is a direct measure of the amount of uranium on the filter paper sample, this amount being proportional to the amount released to the atmosphere; (2) there are no absorption or energy loss problems, and (3) background activity would have a minimal effect. Experimental work showed that this technique had adequate sensitivity, but it was eliminated by one major disadvantage-the radiation hazard associated with the use of either an $X$-ray generator or a high-intensity radioactive source. Either exciter would add to the complexity of the monitoring system as well as contribute to a substantial increase in cost.

\section{Alpha Energy Discrimination}

The alpha energy discrimination method utilizes a silicon-surface-barrier detector with good alpha energy resolution to distinguish between the enriched uranium alpha activity and that of the background. The enriched uranium alphas are primarily from U-234 and have energies of 4.77 and $4.72 \mathrm{Mev}$; whereas, the energies of the alphas from the radon decay series are 6.00 and $7.68 \mathrm{Mev}$. Figure 3 provides a schematic diagram of the alpha energy discrimination system as it would be used in monitoring the stack effluent. A system based upon this same principle of alpha energy discrimination is presently in use at the Oak Ridge National Laboratory. (2)

The alpha energy discrimination method is superior to the system now in use at the $\mathrm{Y}-12$ Plant, especially in the effect that background activity has on the count rate. Whereas the present system has 100 percent sensitivity to
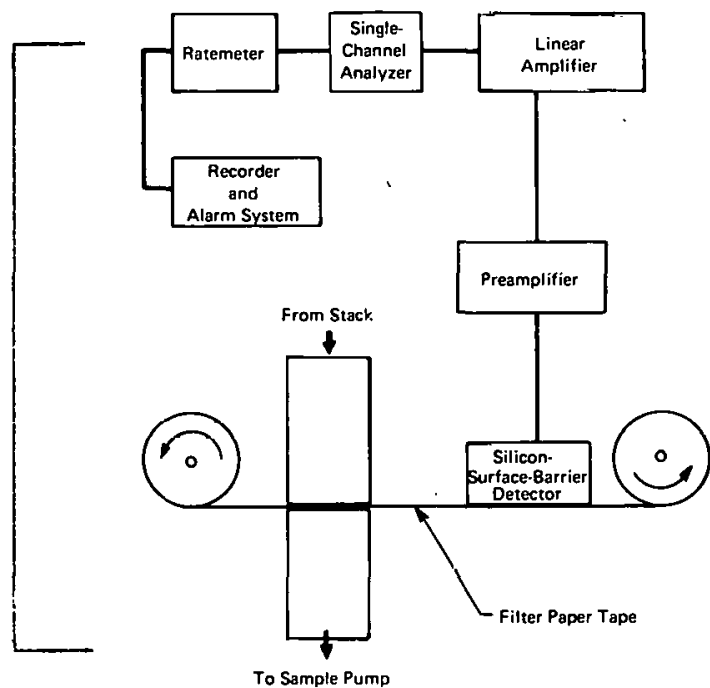

Figure 3. COMPONENTS OF THE ALPHA ENERGY DISCRIMINATION MONITORING SYSTEM. background alpha activity, the alpha energy discrimination method has only 20 percent sensitivity when the optimum SCA energy window is employed. The sensitivity of this method is pointed out in Table 1. Although the experimental mockup used to obtain these data had a geometric efficiency of only 25 percent, one microgram of the enriched uranium could be detected with good counting statistics in count times of less than ten minutes (assuming no radon background activity). This geometric efficiency can be improved to nearly 50 percent with larger detectors and properly designed fixturing, resulting in improved sensitivity or shortened count times. 
Table 1

ENRICHED URANIUM SENSITIVITY OF THE ALPHA ENERGY DISCRIMINATION METHOD

\begin{tabular}{cc}
\hline $\begin{array}{c}\text { Uranium(1) } \\
\text { Content } \\
(\mu \mathrm{gm})\end{array}$ & $\begin{array}{c}\text { Alpha Activity } \\
\text { Optimum Energy } \\
\text { Window } \\
\text { (cpm) }\end{array}$ \\
\hline & \\
41.25 & 275 \\
37.50 & 266 \\
15.55 & 106 \\
5.50 & 45 \\
4.28 & 40 \\
\hline
\end{tabular}

(1) This level of uranium enrichment contains, nominally, $93 \%$ U-235, $1 \%$ U-234, and $6 \%$ other uranium isotopes.
Alpha-energy discrimination does have the drawbacks that are associated with any method that utilizes alpha activity. One drawback is the decrease in observed activity due to absorption of alpha particles in the filter paper. During sample collection, some of the uranium particulates become embedded in the filter paper. Those alphas emitted by these embedded particulates lack sufficient energy to traverse the filter paper thickness and sample-detector air gap, and reach the detector. This inadequate energy means that the observed activity will be less than actual; therefore, a statistically determined correction factor (called paper factor). must be applied to all data to ubtain the correct activity. Because this paper factor can vary significantly from sample to sample, a low reliability of the data results.

The most significant drawbaok for the alpha eriergy discrimination method is the phenomenon of energy loss along the different alpha particle tracks from filter paper to detector, resulting in a broadening of the alpha energy peaks. Figure 4 illustrates this broadening effect with a spectrum in air of uranium on filter paper and one in vacuum of uranium electrodeposited onto a metal disc. As is evident, the energy degradation extends to near zero energy. The importance of this broadening lies in the fact that the background alpha peaks are also broadened, extending the background alpha spectrum into the uranium energy region. Figure 5 illustrates this broadening effect on a uranium spectrum and a radon decay series spectrum. (The radon-decay-series 6.00-Mev peak is not readily discernible due to the short half life of Po-218 and to an unavoidable time delay between sample collection and

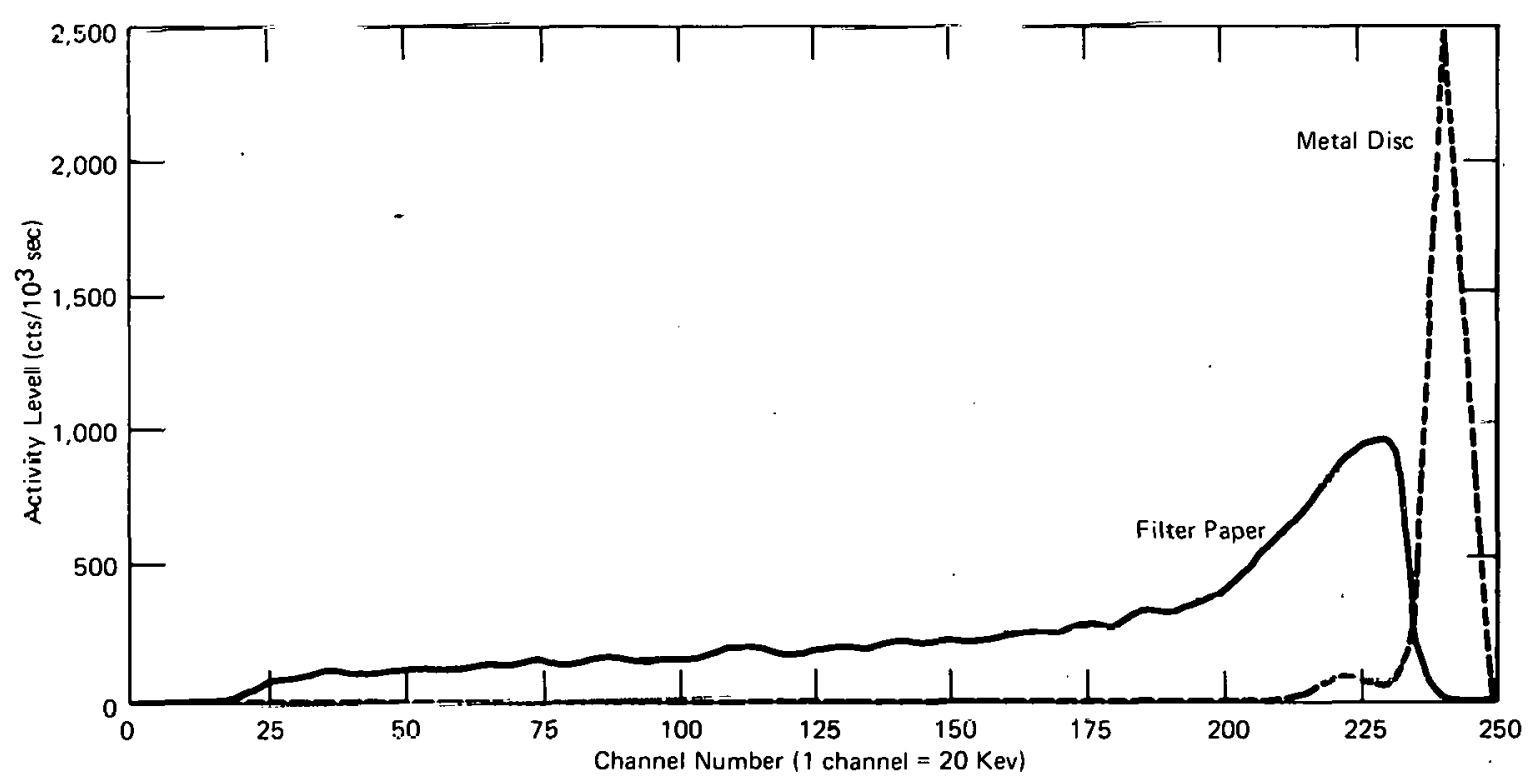

Figure 4. ALPHA ENERGY SPECTRA OF URANIUM ON FILTER PAPER (IN AIR) AND ELECTRODEPOSITED ON A METAL DISC (IN VACUUM). 


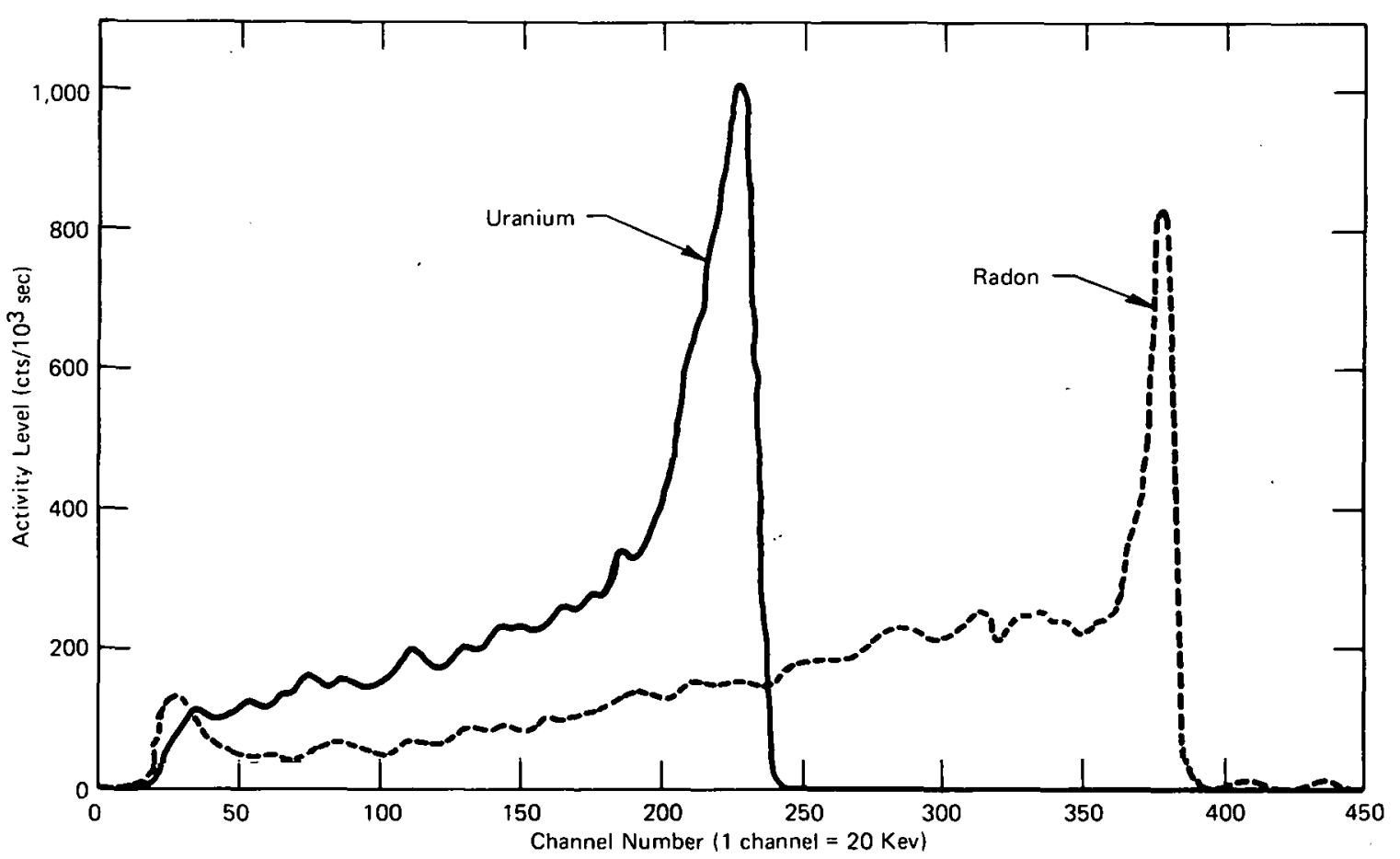

Figure 5. COMPARISON OF URANIUM AND RADON ALPHA SPECTRA.

analysis.) This broadening has the effect of increasing the apparent "uranium" count above that value obtained with only uranium present. If the optimum SCA energy window was used, a radon sample of comparable alpha activity would change the apparent alpha count from a uranium sample by approximately 30 percent. This amount of change does not remain constant but varies as the background activity varies.

Two more problems that have to be considered are: (1) the silicon-surface-barrier detector's light sensitivity, and (2) contamination of the detector and its surroundings by the filter paper samples. Because the silicon-surface-barrier detector is a light-sensitive device, its mounting must be designed to provide a light-tight seal when it analyzes the alpha emissions from a sample. Also, the detector and its surroundings can become contaminated when some of the uranium is separated from the filter paper during analysis, causing two. problems: (1) the sensitivity would be reduced, and (2) there would be an increase in background activity. Contamination can be avoided by covering the filter paper with a thin Mylar film; but, once again, energy resolution would be poor.

Several improvements can be made in the method just described, but greater cost and a more complex mode of operation are required. A minor change that could be easily incorporated into any system is in the choice of filter paper. If a membrane-type filter medium was used, the count-rate loss and energy broadening due to the filter paper would be significantly lessened, since fewer particulates would become deeply embedded. (2) Also, by designing the detector mount and associated fixturing properly, the volume between the detector and filter paper could be evacuated during analysis to minimize the energy loss due 
to the air gap. Figure 6 shows the alpha spectrum of a small amount of uranium on filter paper; first, obtained in air and then obtained with the sample and detector in an evacuated chamber. A third improvement, which means added cost as well as greater complexity of operation, requires the use of a second single-channel analyzer. With the energy window set on a portion of the background alpha spectrum just above the uranium energy region, as indicated in Figure 7, a background count is obtained; and, assuming a constant relationship between this background count and that found in the uranium energy region, a correction can be applied to the apparent uranium count, thereby reducing the effect of the background activity.

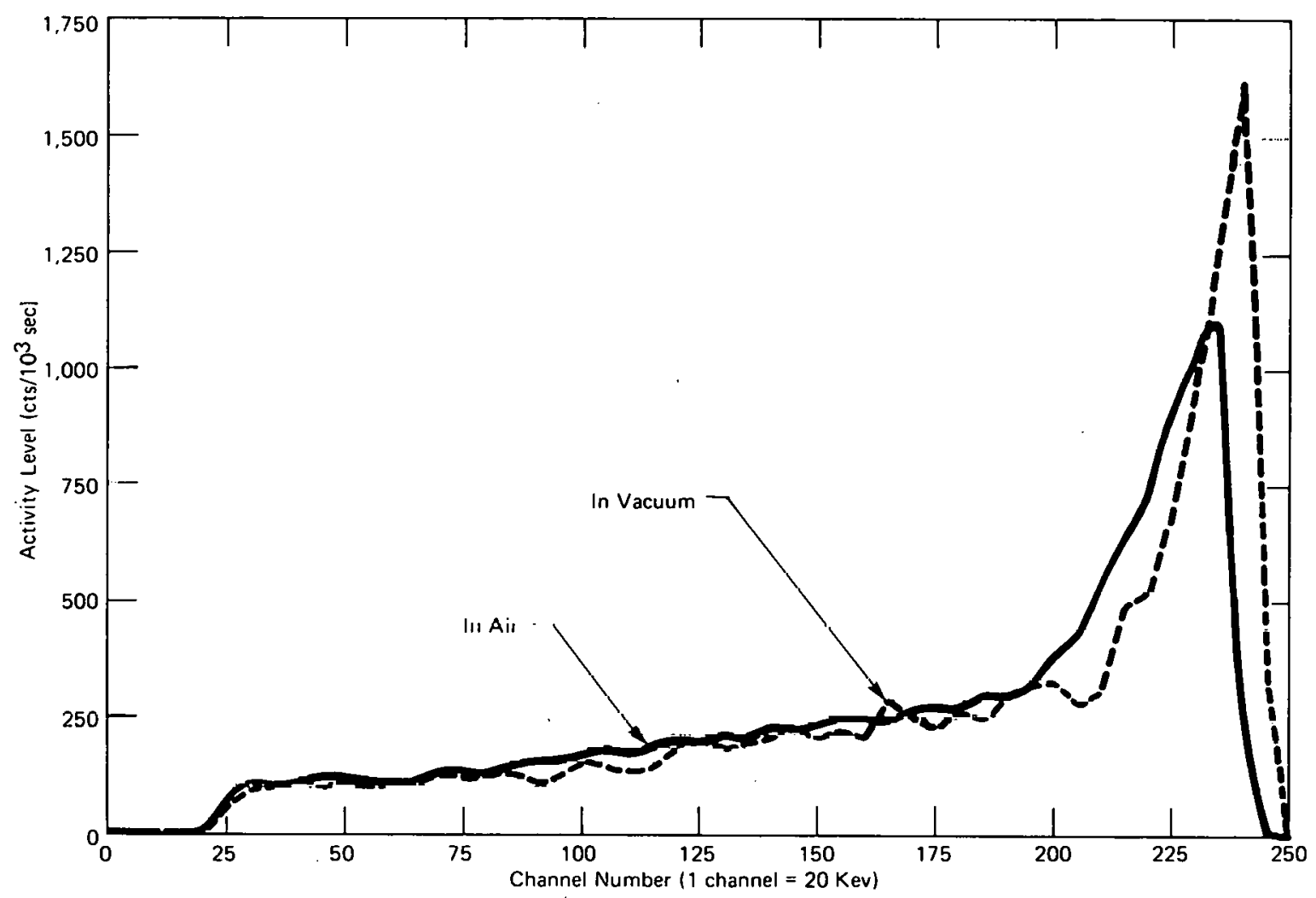

Figure 6. COMPARIȘON OF THE ALPHA SPECTRUM IN AIR AND THE ONE IN VACUUM OF A URANIUM SAMPLE ON FILTER PAPER.

\section{X-May Encrgy Analysis}

Uranium-234 decays by alpha emission to an excited state and the ground state of Th-230. The excited state then decays by internal conversion to the ground state, producing the characteristic $L X$ rays of thorium. For a given amount of enriched uranium, the $L X$-ray activity is approximately 28 percent of the alpha activity. Using either a thin sodium iodide crystal detector or a germanium low-energy-photon (LEP) detector, the thorium $L X$ rays are distinguished from background activity due to the radon decay series. Background $X$ rays, whose energies are close to those of the thorium $L X$ rays, are produced when an excited state of $\mathrm{Bi}-214$ decays by internal conversion to its ground state. The result is the 


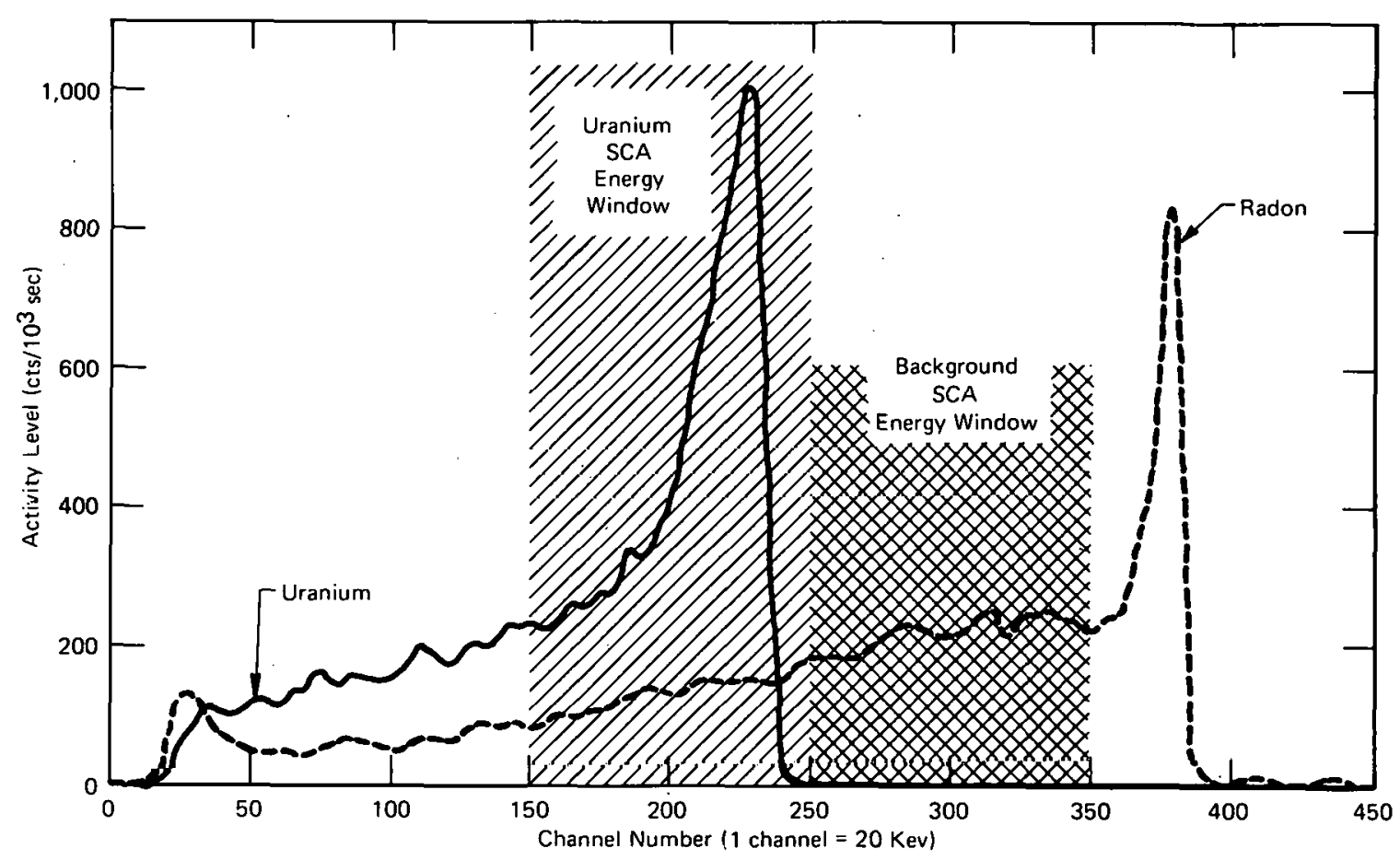

Figure 7. COMPARISON OF THE URANIUM AND RADON ALPHA SPECTRA.

bismuth $L X$ rays. For a given radon sample, the $X$-ray activity is approximately 10 percent of the alpha activity.

The X-ray energy analysis method employs either a thin sodium iodide crystal or a germanium LEP detector to analyze the $X$-ray activity from a stack sample, with each detector having its advantages and disadvantages. The germanium LEP detector offers the advantage of excellent energy resolution coupled with a low background radiation level. By using this detector, the $L_{\beta}$ and $L_{\gamma} X$-ray peaks of thorium can easily be distinguished from the $L X$-ray peaks of bismuth, as can be seen from Figure 8 . If a single-channel-analyzer energy window is set to include only the energy region between and including the thorium $L_{\beta}$ and $L_{\gamma}$ peaks, any background activity due to the radon decay series is greatly reduced if not eliminated. Unfortunately, the detector area is small and provides only a very low count rate. This low count rate places a limit not only on the degree of uranium sensitivity but also on count times, minimizing its usefulness for the problem of measuring small quantities of uranium. Slightly larger detectors than the one used are available, but they are not adequate. Using additional detectors to increase sensitivity and minimize count times is a possibility, but the cost of the system goes up drastically due to the high price of each detector. The thin sodium iodide crystal detector has excellent stopping-power characteristics for low-energy photons; but, for energies above $50 \mathrm{Kev}$, it becomes transparent. Thls property of the crystal makes it possible to detect low-energy activity with greater efficiency than the higher-energy photons. A satisfactory count rate can be realized due to the variety of available detector sizes, and the cost is comparable to that of a silicon-surface-barrier detector. The sodium iodide detector, which was used for the experimental work, has a resolution of 28 percent at $32 \mathrm{Kev}$, but this is not good enough to separate the thorium and bismuth $X$-ray peaks, as seen in Figure 9. 


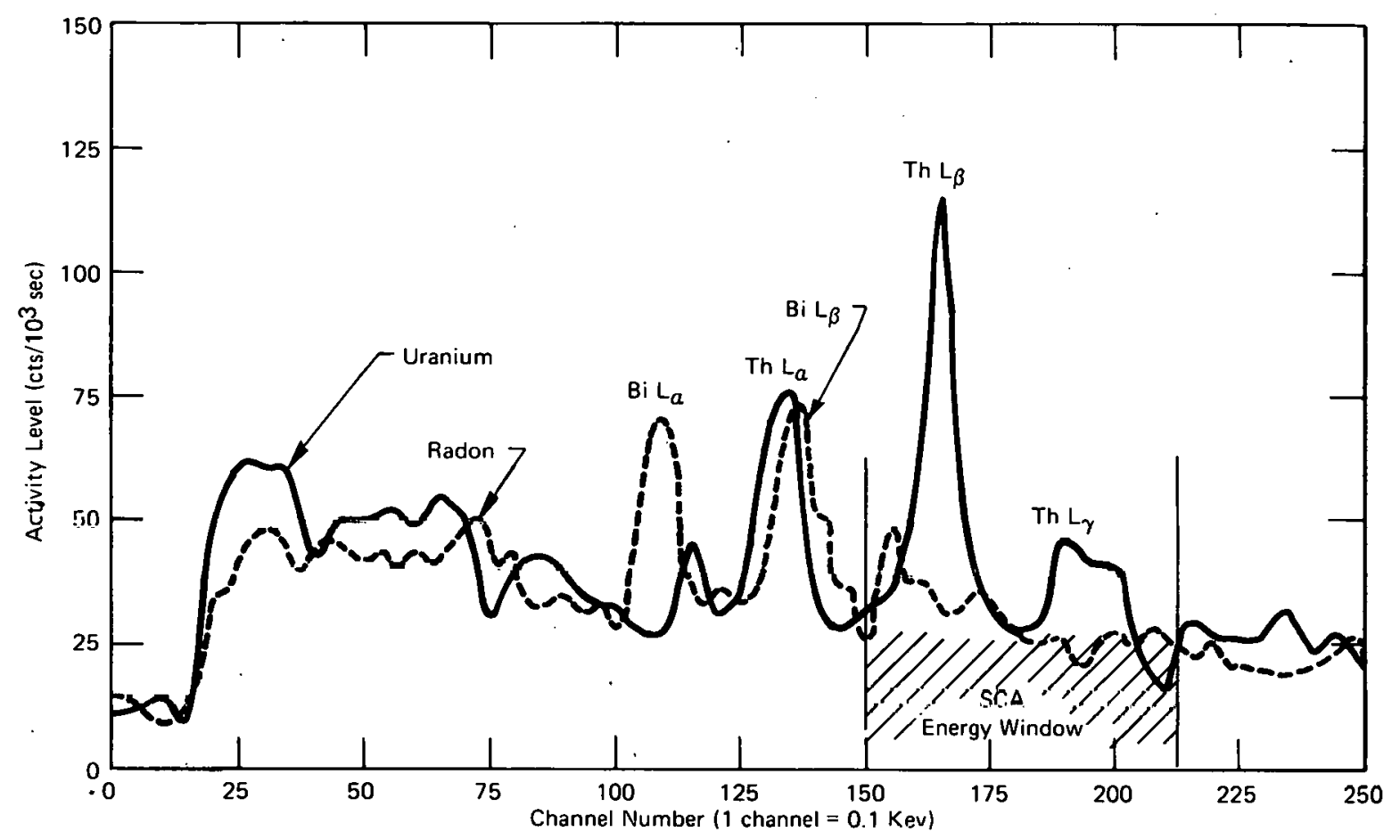

Figure 8. COMPARISON OF THE URANIUM AND RADON X-RAY SPECTRA USING A GERMANIUM LOW-ENERGYPHOTON DETECTOR.

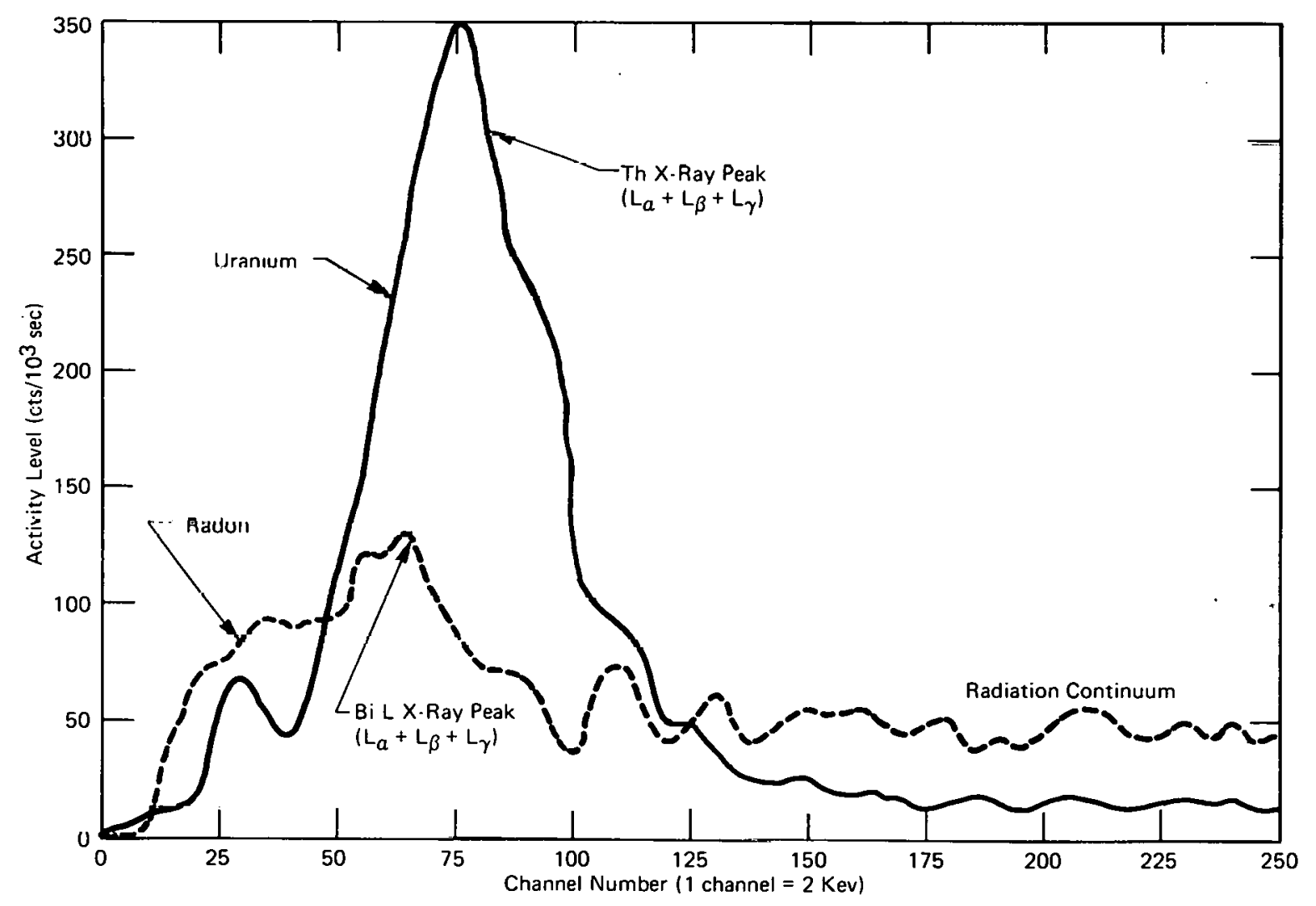

Figure 9. COMPARISON OF URANIUM AND RADON X-RAY SPECTRA USING A THIN SODIUM IODIDE CRYSTAL DETECTOR. 
Since the count rate from the germanium LEP detector was so low, and since no larger detectors were available, emphasis in the experimental work was on the use of the sodium iodide detector. A schematic diagram of the $X$-ray energy analysis method using the thin sodium iodide crystal detector, as it would be when monitoring a stack effluent, is presented in Figure 10. This method has certain advantages over the present monitoring method and

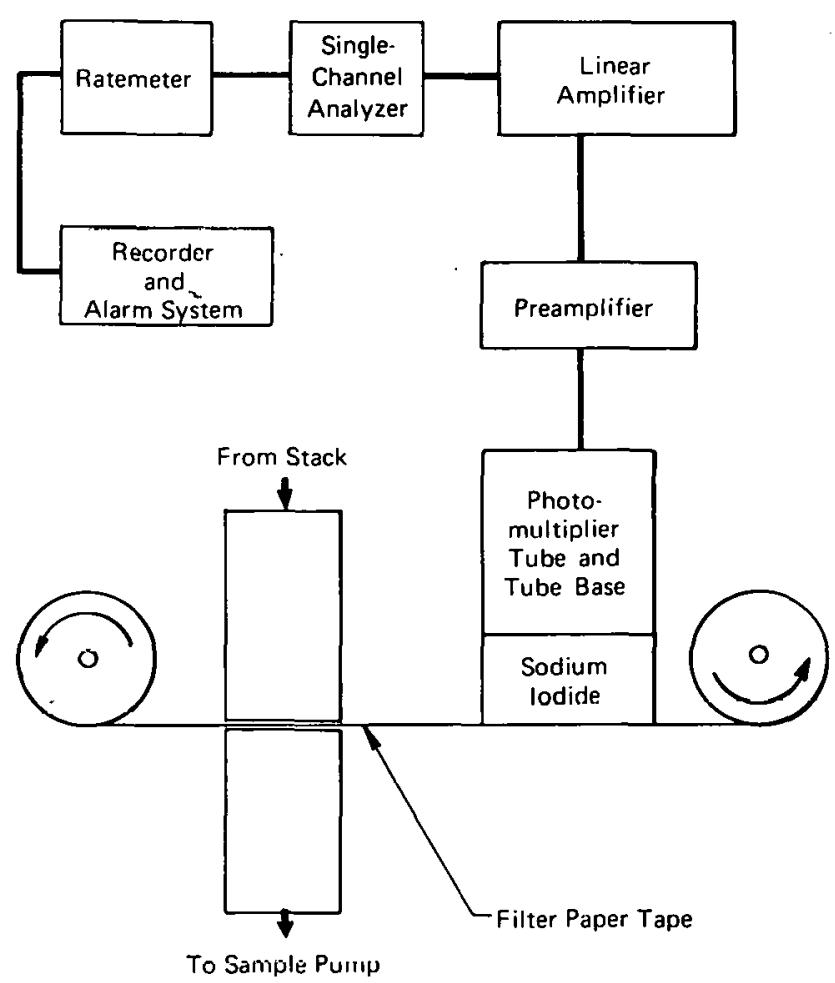

Figure 10. COMPONENTS OF THE X-RAY ENERGY ANALY. SIS MONITORING SYSTEM. the alpha energy discrimination method in that: (1) it has less sensitivity to background activity than the presently used method; (2) the X-ray background activity is less than the alpha activity; (3) there are no significant absorption or energy-loss phenomena associated with the filter paper or air gap; (4) the contamination problem is eliminated by covering the filter paper with a thin Mylar film, which does not affect the measurement. The sensitivity of this method is indicated by the data of Table 2 which show that it is about half that of the alpha energy discrimination method (assuming no radon background activity). The detector geometric efficiency for the experimental setup was 30 percent (which could be improved to nearly 50 percent); and, by using two detectors opposite one another, the $X$-ray energy analysis sensitivity would become comparable to that of the alpha energy discrimination method.

The major disadvantage of the $X$-ray energy analysis method is the relatively poor energy resolution of the thin sodium iodide crystal detector. As Figure 9 points out, the uranium $L$ $X$-ray peak, $\left(L_{a}+L_{\beta}+L_{\gamma}\right)$ and the bismuth $L X$-ray peak $\left(L_{a}+L_{\beta}+L_{\gamma}\right)$ overlap to some extent. If the SCA energy window was set from Channel 50 to Channel 125 loptimum setting), a background sample of comparable activity would change the apparent uranium $X$-ray count by 35 percent. As is the case in the alpha energy discrimination method, the change will vary as the background activity varies, introducing an unknown amount of error.

The $X$-ray energy analysis method can be improved with additional electronics and improved detectors. In Figure 9, a radiation continuum is visible in the radon spectrum. It is felt that this continuum is due to degraded high-energy gammas and high-energy betas. Using an extra SCA with the energy window set to include only a portion of the radiation continuum, and assuming the continuum is of the same intensity in the uranium $X$-ray energy region, the count from this SCA can be used to correct the apparent uranium $X$-ray count from the other SCA. This arrangement would further the reduction of the relative effect of background activity. Another means by which this radiation continuum can be 
reduced is by using a two-scintillation crystal detector which consists of a thin sodium iodide crystal on a thick cesium iodide crystal. Both crystals are mounted on a single photomultiplier tube. By using a pulse-shape discrimination circuit, some of the background due to degraded high-energy gammas can be eliminated, thereby significantly reducing the background activity.

\section{CONCLUSIONS AND RECOMMENDATIONS}

Of the four methods considered as providing an improved enriched uranium monitor, only alpha energy discrimination and X-ray energy analysis proved to be suitable. Each particular application will dictate which of these two methods is best.

The major advantage that alpha energy discrimination has over X-ray energy analysis is its sensitivity to enriched uranium, as the graph of Figure 11 emphasizes. (The data for this graph are from Tables 1 and 2.) Using one detector with a 25 percent geometric efficiency, alpha energy discrimination had a sensitivity $(6.6 \mathrm{cpm} / \mu \mathrm{gm})$ almost twice that of the $X$-ray energy analysis method $(3.4 \mathrm{cpm} / \mu \mathrm{gm})$ which uses a single sodium iodide detector with a 30 percent geometric efficiency. Stated more quantitatively, alpha energy discrimination can

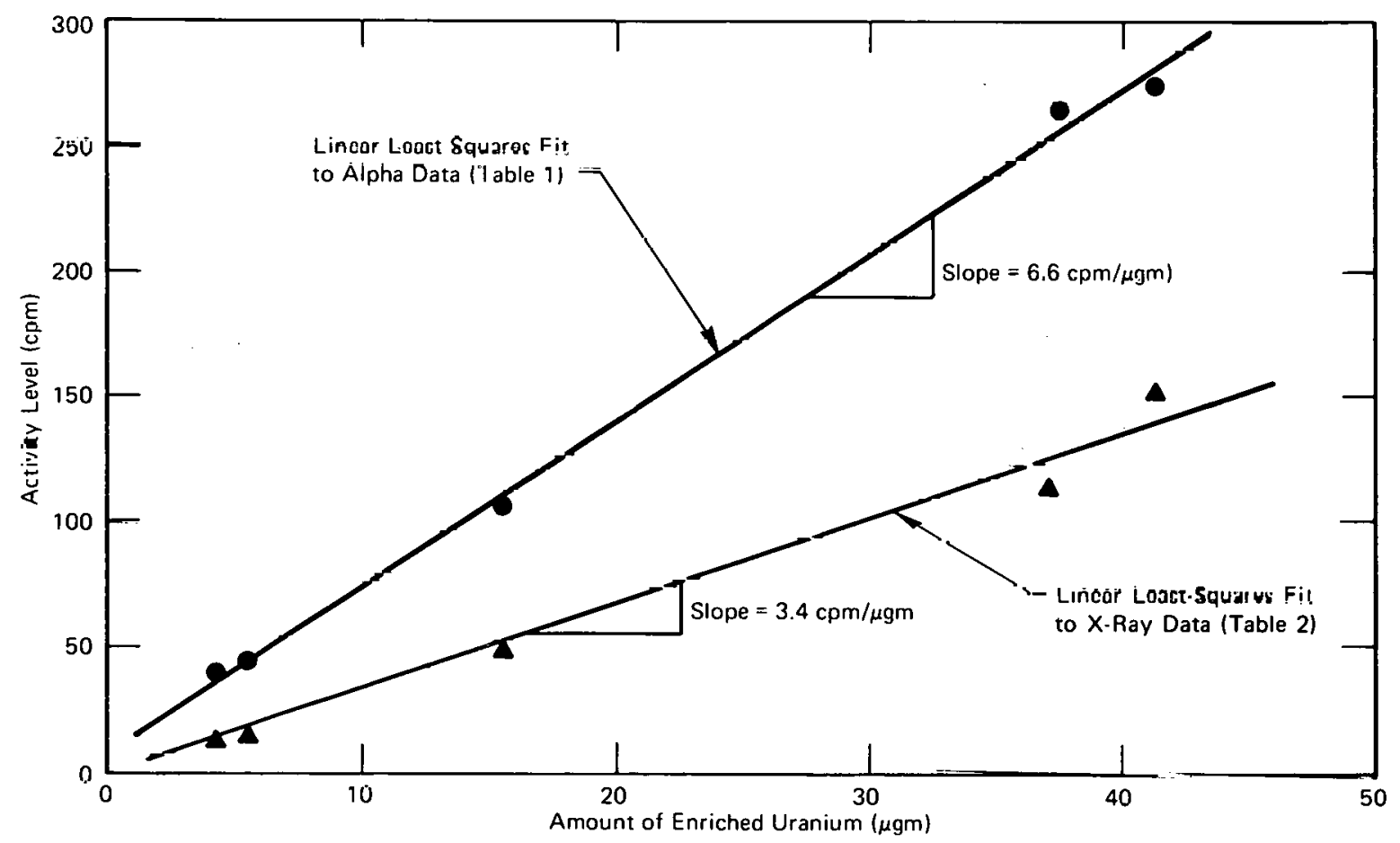

Figure 11. COMPARISON OF THE SENSITIVITIES OF THE ALPHA ENERGY DISCRIMINATION AND X-RAY ENERGY ANALYSIS DETECTION METHODS. 
detect one microgram of enriched uranium with good counting statistics in a 10-minute count time, but $X$-ray energy analysis requires a 20 -minute count time to detect one microgram with similar counting statistics. Another important advantage of the alpha energy discrimination method is the relative effect of the radon background activity on the apparent uranium count. Using the optimum SCA energy window setting of each method, alpha energy discrimination experiences a 30 percent increase in the apparent uranium alpha count due to a radon sample of comparable activity while $X$-ray energy analysis has a 35 percent increase in the apparent $X$-ray count.

But, the alpha energy discrimination method has weaknesses that do not exist in the X-ray energy analysis method. The most serious problems associated with monitoring alpha activity are the absorption of alphas in the filter paper and the energy losses that are experienced along the different alpha particle tracks from filter paper to detector. These problems do not exist with $X$ rays which will pass through filter paper and air with no appreciable attenuation. Also, contamination, which is a serious problem with the alpha energy discrimination method, can be avoided with the $X$-ray method by using a thin Mylar covering on the filter paper tape. Although the $X$-ray energy analysis method has only half the sensitivity of the alpha energy discrimination method, two $X$-ray detectors connected together and located on opposite sides of the filter paper tape can be used to double the count rate and make the two methods comparable in sensitivity to uranium. 


\section{REFERENCES}

(1) Lederer, C. M., Hollander, J. M., and Perlman, Isadore; Table of /sotopes, 6th Edition; John Wiley and Sons, New York (1967).

(2) Shipp, R. L., Jr; Development of Two Systems for Monitoring Alpha-Emitting Particulates in Radioactive Gas Disposal Stacks, ORNL-TM-3165; Union Carbide Corporation-Nuclear Division, Oak Ridge National Laboratory, Oak Ridge, Tennessee; December 29, 1970. 


\section{BIBLIOGRAPHY}

Lockhart, Luther B., Jr; "Radioactivity of the Radon-222 and Radon-220 Series in the Air at Ground Level", The Natural Radiation Environment, University of Chicago Press, Chicago (1964).

Lucas, Henry F., Jr; "A Fast and Accurate Survey Technique for Both Radon-222 and Radium-226", The Natural Radiation Environment, University of Chicago Press, Chicago (1964).

Martz, D. E., Holleman, D. F., McCurdy, D. E., and Schiager, K. J.; "Analysis of Atmospheric Concentrations of RaA, RaB, and RaC by Alpha Spectroscopy", Health Physics, 17, pp 131-138 (1969).

Raabe, Otto G and Wrenn, McDonald E.; "Analysis of the Activity of Radon Daughter Samples by Weighted Least Squares", Health Physics, 17, pp 593-605 (1969).

Spaa, J. H.; "A Rapid Indicating Instrument for the Stepwise Measurement of Air Dust Radloactivity"; Health Physics, 4, pp 25-31 (1960). 


\section{DISTRIBUTION}

Atomic Energy Commission - ORO

Hickman, H. D.

Zachry, D. S., Jr

Dow - Rocky Flats

Cartwright, D. R.

Los Alamos Scientific Laboratory

Walton, R. B.

Oak Ridge Gaseous Diffusion Plant

Wilcox, W. J., Jr

Winkel, R. A.

\section{Oak Ridge National Laboratory}

Knowles, D. J.

Shipp, R. L., Jr

\section{Oak Ridge Y-12 Plant}

Alvey, H. E.

Barkman, J. R.

Burditt, R. B.

Briscoe, O.W.

Burkhart, L. E.

Butturini, W. G.

Choat, E. E.

Cooper, B. E.

Denny, A. (2)

Ebert, J. W.

Ellingson, R. D.

Gallman, R. A. (15)

Gritzner, V. B.

Hemphill, L. F.
Henderson, G. M.

Hensley, C. E.

Hill, D. G.

Jackson, V. C.

Johnson, C. E.

Kahl, K. G.

Keith, Alvin

Mason, D. L.

MiLendon, J. D.

McMalion, G. T.

McNabb, J. E.

Mitchel, G. W.

Oliphant, \& $\mathrm{W}$.

Perry, A. E.

Sanders, $M$.

Smith, H. F., Jr

Smith, R. D.

Snow, S. G.

Snyder, H. G. P.

Stanton, J. A.

Trotter, T. C.

Weathersby, W. E.

West, C. M.

Williams, R. D.

Yaggi, W. I.

Y.12 Central Files (5)

$Y 12$ Central Files (master copy)

$Y$-12 Central Files (route)

$Y-12$ Central Files $(Y-12 R C)$

Paducah Gaseous Diffusion Plant

Edwards, A. K.

In addition, this report is distributed in accordance with the category UC-41, Health and Safety, as given in the USAEC Standard Distribution Lists for Unclassified Scientific and Technical Reporis, TID-4500. 